Aim to:

- Demonstrate the reach and impact of hospice care to commissioners and the community

- Work in partnership to identify economies of scale and potential opportunities for partnership working

- Promote volunteering

- Project a professional impression, working together not against each other

- Establish hospice care as a solution to future challenges in palliative and end-of-life care

- Strengthen understanding of the contribution of hospice care

- Memorandum of Understanding signed by chairs of each Board and CEO.

- Quarterly meetings to review annual work-plan, regular meetings by executive teams to explore potential for future joint projects.

Partnership work so far:

- Joint secondment of an EMIS IT Co-ordinator to ensure consistency in data and reporting. 18 month post, 1 day per week in each hospice

- Joint priorities for improvement in hospice Quality Accounts

- Joint communications strategy - One hospice message

- Joint fundraising events - heads of fundraising working in partnership

We hope that the formation of the Cumbrian Hospice Alliance will allow us to encourage our people to work in partnership to unleash the potential to raise funds and provide more joined-up care for the Cumbrian communities we serve.

\section{P-181 HARNESSING THE POTENTIAL OF WORKING TOGETHER TO TRANSFORM CARE LOCALLY - ST MICHAEL'S HOSPICE AND MARIE CURIE}

${ }^{1}$ Sue Morgan, ${ }^{2}$ Karen Burfitt. ${ }^{1}$ St Michael's Hospice, Hereford, UK; ${ }^{2}$ Marie Curie

\subsection{6/bmjspcare-2016-001245.203}

In less than three months, from point of concept to operational delivery, St Michael's Hospice and Marie Curie, with funding from Herefordshire CCG, have launched a new service that will transform the way palliative and end-of-life care is delivered locally.

The new Herefordshire Hospice at Home service demonstrates what can be achieved when a UK-wide charity and local hospice come together to respond to local demand for new or increased support for people in the last few months and weeks of life, and their families.

The service, co-ordinated by St Michael's Hospice, delivers planned and urgent care $24 / 7$, in people's usual places of residence. It supports discharge from hospital and admission avoidance, and enables more people to die in their preferred place of care.

The challenges of changing demographics and health and care profiles of residents presented a real opportunity to extend the level and accessibility of services provided, and improve care coordination.

Playing to each organisation's strength and acknowledging the differences has led to a truly open partnership. Cross-organisational collaboration, effective resource allocation, recruiting new staff and early engagement with local leaders and professionals have been vital to its early success.

With the support of the St Michael's Hospice hub, the partnership has created the impetus to improve integrated joint working and shared care across acute and community teams, ensuring that each person receives the care they need.

Supporting local professionals' play their part in good end-oflife care is also an important element. Providing access to reactive face to face visits and telephone support 24/7 means that professionals and the people they care for get the urgent support they need at any time of day or night.

Early data shows preferred place of death has been achieved in all patients and hospital admission avoided.

\section{P-182 SOCIAL CARE CHAMPIONS - WORKING IN PARTNERSHIP}

${ }^{1}$ Kevin Chesters, 'Jackie Rutter, 'Lorraine Dunn, ${ }^{2}$ Clare Spencer. ${ }^{1}$ Douglas Macmillan Hospice, Stoke on Trent, UK; ${ }^{2}$ Staffordshire and Stoke on Trent Partnership NHS Trust

\subsection{6/bmjspcare-2016-001245.204}

Following the Social Care Champions Workshop held at Loros Hospice in 2014 the hospice's social work team devised an action plan to identify specific goals from the Framework for Social Care at End of Life, focusing on improving collaborative working with colleagues in adult social care services.

A meeting was arranged in 2016 with a local partnership NHS trust. The aim of the meeting was to explore and identify a realistic plan to forge stronger links between them and the hospice. A proposal was put forward to facilitate a three-day teaching programme to be delivered by lecturing staff within the education department at the hospice for social care colleagues who showed an interest in palliative care.

Course aims were for the participants to have a greater understanding of palliative and end-of-life care, including holistic assessment and communication skills for end-of-life and for them to be able to relate these to their own areas of professional practice.

The pilot teaching programme was delivered to a cohort of 16 social care staff. The feedback from the course participants was extremely positive and further cohort of the same training has already been commissioned by the local NHS trust.

Further collaboration has followed on from this project and an event has been organised to promote the resource 'The Role of the Social Worker in Palliative, End of Life and Bereavement Care'. This has involved the palliative care social workers from four regional hospices engaging with a Social Work Teaching Pilot and the staff from its partnership agencies. The aims of the event are to look at how people can get the most out of social work and how stronger links can be developed to support the delivery of high quality end of life care.

\section{P-183 FIT FOR FUTURE? PARTNERSHIP OR PERISH}

Ann Lee, Joy Milliken, Kate Sutor. St Margaret's Hospice, Taunton, UK

\subsection{6/bmjspcare-2016-001245.205}

A strategic appraisal of end-of-life care in a rural county, with a view to planning sustainable and effective hospice care for the next ten years and beyond.

Challenge how to sustain outstanding end-of-life care in a rural county dealing with rising demand, an ageing population, increased complex comorbidities, tightening funding and finances and a diminishing skilled workforce. 